\title{
Relationship between lipid profiles with carotid intima-media thickness in children with type I diabetes mellitus
}

\author{
Rubiana Sukardi $^{1}$, Bambang Madiyono ${ }^{1}$, Sudigdo Sastroasmoro ${ }^{1}$, Jose RL Batubara ${ }^{2}$
}

\begin{abstract}
Background The major cause of morbidity and mortality in patients with type I diabetes mellitus is premature and extensive artherosclerosis. Carotid intima-media thickness (IMT) is associated with cardivascular risk factors and has been used as a marker of early artherosclerosis process.

Objective To determine IMT of carotid artery and its relationship with duration of diabetes, lipid profiles, and mean $\mathrm{HbA}_{1}$ level.

Methods A cross-sectional study was conducted on patients with type $1 \mathrm{DM}$ at the Department of Child Health Cipto Mangunkusumo Hospital. Ultrasound B-mode imaging was performed to measure the IMT. Age-matched non-diabtetic subjects served as controls. Statistical significant was assumed at $\mathrm{P}<0.5$.

Results The mean IMT values of type I DM patients aged $<12$ years, $12-18$ years, $18+$ years were $0.44(\mathrm{SD} 0.03) \mathrm{mm} ; 0.46$ $(\mathrm{SD} 0.01) \mathrm{mm} ; 0.51(\mathrm{SD} \mathrm{0.01)} \mathrm{mm}$, respectively, which were significantly greater than those of age-matched non-diabetic subjects which were 0.39 (SD 0.01), 0.41 (SD 0.01) mm, 0.46 (SD 0.01) mm, respectively. Patients with type I DM had a higher apolipoprotein-B and HDL cholesterol levels than in nondiabetic subjects. Multiple regression analysis showed that there was no relationship between total cholesterol, cholesterol LDL, chronic hyperglycemia $\left(\mathrm{HbA}_{1}\right)$ and IMT. However, IMT in type I diabetes was linearly related with duration of diabetes .

Conclusion Type I DM patients have greater IMT and higher mean apolipoprotein B. There is a strong correlation between IMT and duration of diabetes. [Paediatr Indones 2008;48:14751].
\end{abstract}

Keywords: type I DM, Carotid artery tunica intimamedia thickness, duration of diabetes, lipid profile. he major cause of morbidity and mortality
in patients with type 1 insulin-dependent
diabetes mellitus (type $1 \mathrm{DM}$ ) is premature
and extensive atherosclerotic cardiovascular disease. ${ }^{1,2}$ Although atherosclerotic effects do not appear in most patients until middle age, the process develops earlier. ${ }^{3,4}$ Diabetes mellitus is a wellestablished risk factor for lipid abnormalities and this condition has a positive relationship with early atherosclerotic process. ${ }^{5}$ Carotid intima-media thickness (IMT) is associated with cardiovascular risk factors and has been used as a marker of early atherosclerotic process for other vessels. ${ }^{6,7}$ Identifying atherosclerosis in children can be done using highresolution B-mode imaging of the carotid artery.

No study has been done to specifically determine the relationship of the intima-media thickness (IMT) of carotid artery and its relationship with duration

From the Divison of Pediatric Cardiology, Department of Child Health, University of Indonesia, Dr. Cipto Mangunkusumo Hospital (RS, BM, SS). ${ }^{1}$ The Division Of Pediatric Endocrinology, Department of Child Health, University of Indonesia, Dr. Cipto Mangunkusumo Hospital, Jakarta, Indonesia (JRLB). ${ }^{2}$

Reprint requests to: Rubiana Sukardi, MD, Department Of Child Health, University of Indonesia, Dr. Cipto Mangunkusumo Hospital, Jl. Salemba 6, Sekip, Jakarta, Indonesia. Tel. 62-21-3907742. Fax. 62-21-3907743. E-mail:madarina@pediatric-gmu.org, madarinajulia@yahoo.com 
of diabetes, lipid profiles, and mean $\mathrm{HbA}_{1}$ level of children with Tipe I DM. We propose to determine those relationships in a cross sectional analytic study.

\section{Methods}

This study was performed on 29 children with type $1 \mathrm{DM}$ and 27 healthy children as the control group who were matched in term of age, gender, and body size. Type $1 \mathrm{DM}$ patients were recruited by consecutive sampling from patients who visited Pediatric Endocrinology outpatient clinic of Cipto Mangunkusumo Hospital. The inclusion criteria were diabetic children with minimal duration of illness of two years and did not have any chronic disease other than type $1 \mathrm{DM}$.

\section{Ultrasound studies}

Carotid intima media thickness was measured using Sonos 4500 echocardiography machine with a 12.0$\mathrm{MHz}$ transducer. Scanning of carotid artery was performed while the patients lying on supine position, the head directed away from side of examination, and the neck slightly extended. The proximal part of carotid bulb was identified on both sides, and the segment of common carotid artery located on $1-2 \mathrm{~cm}$ proximal to the bulb was used as the focal zone. Ultrasound scans were performed by a senior Pediatric Cardiology fellow who was not aware whether the subjects belonged to the case or control group. The mean of 6 arterial ( 3 from the left and 3 from the right carotid artery) wall segments, was used in the analysis.

\section{Serum lipids, apolipoprotein B and and serum HbA1 level}

Venous blood specimens were taken after an overnight or 8-10 hour fasting. Total serum cholesterol, LDL cholesterol, HDL cholesterol, triglyceride, apolipoprotein-B, were measured by standard enzymatic methods. Classification of cholesterol level was based on classification from Expert Panel on Blood Cholesterol Level in Children. ${ }^{8} \mathrm{HbA}_{1}$ level plus 3 previous $\mathrm{HbA}_{1}$ values, considered as the mean of $\mathrm{HbA}_{1}$ level, was also assessed by standard enzymatic methods. ${ }^{9}$

\section{Statistical analyses}

Results were expressed as mean (SD) and comparison between 2 groups (type $1 \mathrm{DM}$ and the controls) were conducted by Student's $t$ test or $\mathrm{X}^{2}$ test. Anova test was used for comparison between 3 groups or more. Multiple linear regression technique was used to analyze the independent variables for IMT. All statistical analysis was performed with SPSS version 10.0 for Windows ${ }^{\circledR}$.

\section{Results}

The mean age of the subjects was 15.3 (SD 6) years with a range of 6.7-31 years, while the mean duration of illness was 6.7 (SD 5.27) years. The characteristics of the study groups are shown in Table 1 .

Table 2 shows that the prevalence of high normal systolic blood pressure (BP) in diabetic patients aged 1-17 years was higher than that of the control group, while diastolic BP in all age groups of diabetic patients were significantly higher than that in non-diabetic subjects.

The mean serum apolipoprotein-B and HDL cholesterol levels were significantly higher in type 1 DM compared with those in the control group. However, total cholesterol level in type 1 DM group is higher than that in control group, but the difference was not statistically significant (Table 3 ).

IMT values of children with type $1 \mathrm{DM}$ in all age groups were significantly greater than those of their counterpart (Table 4).

The longest duration of diabetes illness in our study was 15 years and the largest IMT was $0.57 \mathrm{~mm}$.

Table 1. Characteristics of the study subjects

\begin{tabular}{lccc}
\hline \multirow{2}{*}{ Characteristics } & \multicolumn{2}{c}{ Group } & Total \\
\cline { 2 - 3 } & $\begin{array}{c}\text { Type 1 DM } \\
\mathrm{n}=29\end{array}$ & $\begin{array}{c}\text { Control } \\
\mathrm{n}=27\end{array}$ & $\mathrm{n}=56$ \\
\hline Sex & 6 & 8 & 14 \\
$\quad$ Male & 23 & 19 & 42 \\
$\quad$ Female & & & \\
\hline Age group & 9 & 11 & 20 \\
$<12$ years & 11 & 6 & 17 \\
12-18 years & 9 & 10 & 19 \\
$>18$ years & & & \\
\hline
\end{tabular}


Analysis of variance showed that an increasing duration of diabetes was associated with increasing IMT (Table 5). Moreover, there was also a significant linear correlation between duration of diabetes and IMT $(\mathrm{r}$ : $0.738 ; \mathrm{P}<0.0001)$; with a regression equation formula

Table 2. Distribution of blood pressure measurements among subjects

\begin{tabular}{|c|c|c|c|c|}
\hline & $\begin{array}{c}\text { Type 1 DM } \\
(\mathrm{n}=29)\end{array}$ & $\begin{array}{l}\text { Control } \\
(n=27)\end{array}$ & Total & $P^{*}$ \\
\hline \multicolumn{5}{|l|}{ Systolic blood pressure } \\
\hline \multicolumn{5}{|l|}{ Age $1-17 y^{* s^{* *}}$} \\
\hline Normal & 15 & 17 & 32 & 0.036 \\
\hline High normal & 5 & 0 & 5 & \\
\hline \multicolumn{5}{|l|}{ Age $>18 \mathrm{yrs}^{* * *}$} \\
\hline Normal & 2 & 6 & 8 & 0.187 \\
\hline Prehypertension & 6 & 4 & 10 & \\
\hline Level 1 hypertension & 1 & 0 & 1 & \\
\hline \multicolumn{5}{|l|}{ Diastolic blood pressure } \\
\hline \multicolumn{5}{|l|}{ Age $1-17 \mathrm{yrs}^{\star *}$} \\
\hline Normal & 10 & 17 & 27 & 0.001 \\
\hline High normal & 10 & 0 & 10 & \\
\hline \multicolumn{5}{|l|}{ Age $>18 \mathrm{yrs}^{\star \star *}$} \\
\hline Normal & 0 & 5 & 5 & 0.026 \\
\hline Prehypertension & 7 & 5 & 12 & \\
\hline Level 1 hypertension & 2 & 0 & 2 & \\
\hline
\end{tabular}

Table 3. Distribution of lipid profiles in diabetic patients and in the control group.

\begin{tabular}{lccccc}
\hline \multirow{2}{*}{$\begin{array}{c}\text { Lipid profiles } \\
(\mathrm{mg} / \mathrm{dL})\end{array}$} & \multicolumn{6}{c}{ Type 1 DM $(\mathrm{n}=29)$} & \multicolumn{3}{c}{ Control $(\mathrm{n}=27)$} & \multirow{2}{*}{$\mathrm{P}^{*}$} \\
\cline { 2 - 5 } & Mean & SD & Mean & SD & \\
\hline Total cholesterol & 180.9 & 40 & 143.3 & 15.5 & 0.093 \\
LDL cholesterol & 112.9 & 34.5 & 94.6 & 19.5 & 0.187 \\
HDL cholesterol & 52.1 & 10.4 & 43.4 & 8.2 & 0.001 \\
Triglyceride & 72.4 & 25.9 & 73.2 & 24.7 & 0.831 \\
Apolipoprotein-B & 84.9 & 24.5 & 74.2 & 15.2 & 0.054 \\
\hline SD= standard deviation; *t-test & & & &
\end{tabular}

$\mathrm{SD}=$ standard deviation; *t-test

Table 4. IMT values in diabetic and control subjects

\begin{tabular}{lcccccc}
\hline \multirow{2}{*}{ Age groups } & \multicolumn{2}{c}{ Type 1 DM $(\mathrm{n}=29)$} & \multicolumn{2}{c}{ Control $(\mathrm{n}=27)$} & \multirow{2}{*}{$\mathrm{P}^{*}$} \\
\cline { 2 - 5 } & Mean $(\mathrm{mm})$ & $\mathrm{SD}$ & Mean $(\mathrm{mm})$ & $\mathrm{SD}$ & \\
\hline$<12$ yrs & 0.4 & 0.03 & 0.4 & 0.01 & $<0.0001$ \\
$12-18$ yrs & 0.5 & 0.03 & 0.4 & 0.01 & 0.001 \\
$>18$ yrs & 0.5 & 0.04 & 0.5 & 0.01 & $<0.0001$ \\
\hline SD $=$ Standard of deviation *t test & & & & \\
\end{tabular}

as follows: $\operatorname{IMT}(\mathrm{mm})=0.430+[0.0006 \mathrm{x}$ duration of illness (yrs)] (Figure 1).

Nineteen out of 29 patients showed $\mathrm{HbA}_{1}$ criteria at the high risk level, but analysis of variance showed $\mathrm{HbA}_{1}$ were independently associated with an increase of IMT (Table 6). The effect on IMT was not explained by the mean $\mathrm{HbA}_{1}$ level.

As many variables may be related to IMT, we performed multiple logistic regresion to simultaneously assess the independent association of these variables. Multivariate analysis identified 3 variables, namely age, systolic blood pressure, and duration of illness, as the factors determining thickness of the carotid arterial wall (Table 7).

\section{Discussion}

The subjects in this study were recruited from all type $1 \mathrm{DM}$ patients who were still actively visiting Endocrinology outpatient clinic, hence the age range

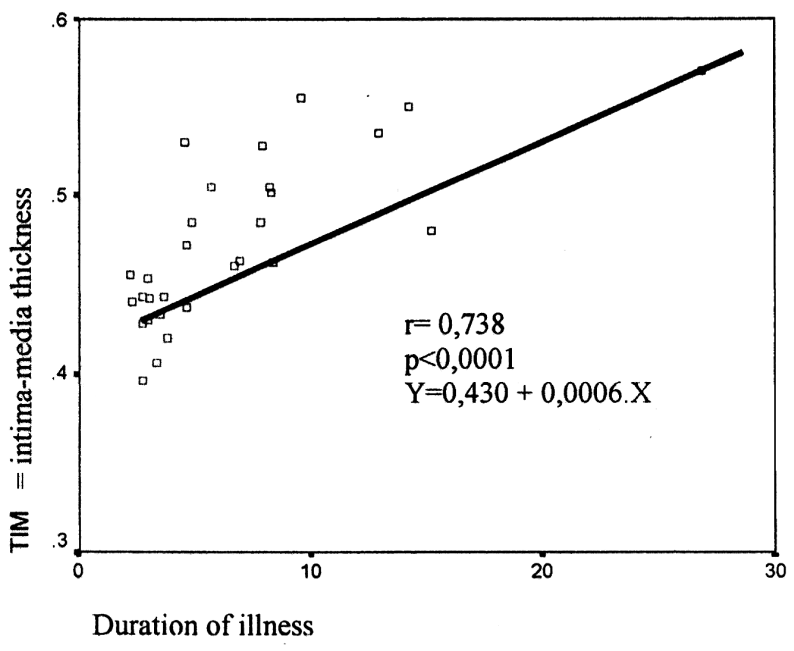

Figure 1. Correlation between IMT and duration of illness.

Table 5. Mean of IMT by duration of diabetes illness

\begin{tabular}{lcccr}
\hline \multirow{2}{*}{ Duration of illness } & $\mathrm{n}$ & Mean of IMT & \multirow{2}{*}{ SD } & $\mathrm{P}$ \\
\cline { 2 - 3 } & $($ Total 29$)$ & $(\min -\max )$ & & \\
\hline$<3$ yrs & 7 & $0.44(0.40 ; 0.46)$ & $0.02<0.0001$ \\
$3-5.9$ yrs & 10 & $0.46(0.41 ; 0.53)$ & 0.04 \\
$6-8.9$ yrs & 7 & $0.51(0.46 ; 0.53)$ & 0.03 \\
$\geq 9$ yrs & 5 & $0.54(0.48 ; 0.57)$ & 0.03 \\
\hline
\end{tabular}

$\mathrm{SD}=$ Standard of deviation; *Analysis of variance (ANOVA) 
Rubiana Sukardi et al: Lipid profiles and carotid thickness in children type I diabetes mellitus

Table 6. The comparison of IMT between $\mathrm{HbA} 1$ criteria

\begin{tabular}{lcccc}
\hline \multirow{2}{*}{ HbA1 criteria } & $\mathrm{n}$ & Mean of IMT & \multirow{2}{*}{ SD } & $\mathrm{P}$ \\
\cline { 2 - 3 } & $($ Total 29$)$ & $($ min - max $)$ & & \\
\hline Optimal & 3 & $0.49(0.46 ; 0.55)$ & 0.05 & 0.539 \\
Suboptimal & 7 & $0.46(0.40 ; 0.53)$ & 0.05 & \\
High risk & 19 & $0.47(0.43 ; 0.59)$ & 0.04 & \\
\hline SD= Standard of deviation & *Analysis of variance (ANOVA)
\end{tabular}

Table 7. Multivariate analysis of various determinants for IMT

\begin{tabular}{lcc}
\hline Variables & Coefficient regression $\beta$ & $\mathrm{P}$ \\
\hline Age & 0.77 & 0.001 \\
Total cholesterol & 0.24 & 0.569 \\
LDL Cholesterol & 0.03 & 0.91 \\
HDL Cholesterol & 0.22 & 0.325 \\
Triglyceride & 0.17 & 0.523 \\
Apolipoprotein-B & 0.04 & 0.85 \\
Mean HbA1 level & 0.063 & 0.744 \\
Systolic blood pressure & 0.54 & 0.003 \\
Diastolic blood pressure & 0.33 & 0.079 \\
Duration of illness & 0.74 & $<0.0001$ \\
\hline
\end{tabular}

was wide. Jarvisalo ${ }^{10,11}$ in his study recruited subjects with narrower age group, i.e. $11(\mathrm{SD} 2)-(\min 8-$ max 18) year-old and shorter duration of illness 4.4 (SD 3) years.

Diastolic hypertension is known to occur frequently in the diabetic population and may be related to diabetic microangiopathy. ${ }^{12}$ Becker ${ }^{13}$ found that mean $\mathrm{ABP}$ is higher in type $1 \mathrm{DM}$ with microvascular complication. Patrikiou-Peppa et $a^{14}$ showed in their study that the systolic and diastolic blood pressures between cases and controls were not significantly different, while Hayaishi-Okano ${ }^{15}$ found significantly higher diastolic $\mathrm{BP}$ in patients with type $1 \mathrm{DM}$. This study revealed the frequency of high normal systolic blood pressure in patients aged $1-17$ years and diastolic $\mathrm{BP}$ in all age groups, were significantly higher than in non-diabetic subjects.

Current studies show that cholesterol level in type 1 DM subjects varies. Lipman ${ }^{16}$ found $34 \%$ of his subjects showed the cholesterol level above $75^{\text {th }}$, while Jarvisalo ${ }^{17}$ found total cholesterol and LDL were similar between diabetic patients and the controls.

The mechanisms of acceleration of atherosclerotic process in diabetes are multifactorial and have not been fully understood. Postsecretory modification of LDL particles (LDL oxidation and glycation) have been proposed as potential causative agents. Kawamory and Kanters investigated patients with type 1 DM aged 21 - 26 years, revealed positive correlation between IMT and hyperlipidemia, ${ }^{18}$ but Tostand and Virkola were not able to show a significant relationship between carotid IMT and normal serum LDL. ${ }^{19,20}$ They assumed LDL concentration, even if within a normal range, was an important determinant of structural arterial changes.

This study showed that apolipoprotein-B, total cholesterol, and LDL levels were higher in type $1 \mathrm{DM}$ patients than those in the controls, but this study showed lack of association between IMT and apolipoprotein-B, total cholesterol, and LDL levels. We assume that other unmeasured factors; such as very-low-density lipoprotein, intermediate-density lipoprotein, may also play a role on higher IMT in individual with diabetes, which were not evaluated in this study.

Jarvisalo ${ }^{13}$ measured IMT in type $1 \mathrm{DM}$ patients with a mean age of 11 years and duration of illness of 4.4 years; they found IMT of 0.44 (SD 0.04) mm, similar with that found in our subjects of $<12$ years old age group. If we compare our IMT at age group $>18$ year old with Okano ${ }^{15}$ study, Okano subjects showed greater IMT. Our study revealed a strong correlation between IMT and duration of diabetes. Patrikiou-Peppa ${ }^{14}$ showed increased tunica intimamedia thickness after duration of illness of 8.8 (SD 5.9) years, while Singh's study ${ }^{21}$ showed that children with type $1 \mathrm{DM}$ developed endothelial dysfunction within the first decade after the onset of diabetes.

An unexpected finding in this study is that higher risk level of $\mathrm{HbA}_{1}$ did not significantly correlate with IMT. Kawamory ${ }^{19}$ and Pujia ${ }^{22}$ in their studies also found no correlation between high mean $\mathrm{HbA}_{1}$ level and increased IMT. Although all of the subjects showed above ideal level of $\mathrm{HbA}_{1}$, there was no correlation with the increased IMT. It may because we included a relatively small numbers of participants.

This study had some limitations. Firstly, although we have recruited most of our diabetic patients, the number of subjects included in this study was relatively small. Secondly, the correlation found did not determine when the process begins. Thirdly, since we did not have a 5-20 MHz vascular transducer which preferable than sectoral transducer $12 \mathrm{~S}$, several measurement from each side of carotid artery was representative for evaluating the IMT. 
Rubiana Sukardi et al: Lipid profiles and carotid thickness in children type I diabetes mellitus

We conclude that carotid IMT in type 1 DM patients is thicker than that in healthy persons and this thickness correlates with the duration of diabetes. Carotid ultrasound is a safe invasive modality in assessing sub-clinical atherosclerosis process, and IMT measurement can provide a useful surrogate marker for atherosclerosis disease. These data may have implications in the treatment of pediatric patients with diabetes. A prospective study needs to be done to evaluate the progress of the IMT. Since atherosclerosis process could be detected non-invasively by measuring carotid IMT, vascular echocardiography evaluation is suggested to be done routinely, despite normal lipid profiles.

\section{References}

1. Betteridge DJ. Diabetes, lipoprotein metabolism, and atherosclerosis. Brit Med Bull 1989;45:285-311.

2. Gracia MJ, McNamara PM, Gordon T, Kannell WB. Morbidity and mortality in diabetes in the Farmingham's population. Diabetes 1997;23:105-11.

3. Donaghue RP, Orchad TJ. Diabetes mellitus and micro vascular complication. An epidemiological perspective. Diab Care 1992;15:1141-55.

4. Bereson GS, Srinivasan SR, Bao W, Newman WP, Tracy RE, Westtigney WA. Association between multiple cardiovascular risk factors and atherosclerosis in children and young adult. $\mathrm{N}$ Engl J Med 1998;338:1650-6.

5. Sperling MA. Diabetes mellitus. In: Sperling MA, editor. Pediatric endocrinology. 2nd ed. Philadelphia: Saunders; 2002. p. 323-66.

6. Singh TP, Groehn H, Kazmers A. vascular function and carotid intima-media thickness in children with insulin-dependent diabetes mellitus. J Am Coll Cardiol 2003;41:661-5.

7. Fathi R, Marwick TH. Noninvasive test of vascular function and structure: Why and how to perform them. Am Heart J 2001;141:694-703.

8. American Academy of Pediatrics, Committee on Nutrition. Cholesterol in childhood. Pediatrics 1998;101:141-7.

9. Indriyanti RS. Pemeriksaan laboratorium untuk diagnosis dan pemantauan diabetes mellitus. Forum diagnosticum. $2003 ; 4$

10. Jarvisalo MJ, Raitakari M, Tiokka JO, Putto-Laurila A, Rontu $\mathrm{T}$, Laine $\mathrm{S}$, et al. Endothelial dysfunction and increase arterial intima-media thickness in children with type 1 diabetes.
Circulation 2004;109:1750-5.

11. Jarvisalo MJ, Putto-Laurila A, Jaratti L, Letimaki T, Solakivi T, Ronnemaa T, et al. Carotid intima-media thickness in children with type 1 diabetes. Diabetes 2002;51:493-8.

12. MC Hill HC, Arias-Stella J, Carbonell LM, Cornea P, De Vaaryearsa EA, Donoso S, et al. Relationship of atherosclerosis in young men to serum lipoprotein cholesterol concentration and smoking. JAMA 1990;264:3018-24.

13. Becker DJ. Complications of insulin-dependent diabetes mellitus in childhood and adolescence. Pediatric Endocrinology 1996;593-605.

14. Patrikiou-Peppa M, Scordili M, Antoniou A, Giannaki M, Dracopolou M, Dacau-Vountakis C. Carotid atherosclerosis in adolescents and young adults with IDDM. Diabetes care 1998;21:1004-7.

15. Hayaishi-Okano R, Yamasaki Y, Katakam N, Ohtoshi K, Gorgawa S, Kuroda A. Elevated C-reactive protein associates with early-stage carotid atherosclerosis in young subjects with type 1 diabetes. Diabetes care 2002;25:1432-8.

16. Lipman TH, Hayman LL, Fabian CV, Difazio DA, Male PM, Goldsmith BM. Risk factors for cardiovascular disease in children with type 1 diabetes. Nursing research 2000;49:27-81.

17. Jarvisalo MJ, Jaratti L, Nanato-Salonen K, Irjala K, Ronnemaa T, Hartiala JJ, et al. Increase aortic intima-media thickness a marker of preclinical atherosclerosis in high risk children. Circulation 2001;104:2943-7.

18. Kawamori R, Yamasaki Y, Matsushima H, Nizhizawa H, Nao $\mathrm{K}$, Hougaku $\mathrm{H}$, et al. Prevalence of carotid atherosclerosis in diabetic patients: ultrasound high-resolution B-mode imaging on carotid arteries. Diabetes Care 1992;15:1290-4.

19. Tonstad J, Joakimsen O, Stensland-Bugge E, Leren TP, Ose L, Russel D, et al. Risk factors related to carotid intimamedia thickness and plaque in children with familial hypercholesterolemia and control subjects. Arterioscler Thromb Vasc Biol 1996;16:984-91.

20. Virkola K, Posonen E, Akerblom HK, Siimes MA. Cholesterol and carotid artery wall in children and adolescents familial hypercholesterolemia: a control study by ultrasound. Acta Pediatr 1997;86:1203-7.

21. Singh TP, Groehn H, Kazmers A. Vascular function and carotid intima-media thickness in children with insulin-dependent diabetes mellitus. J Am Coll Cardiol 2003;41:661-5.

22. Pujia A, Gnasso A, Irace C, Colonna A, Mattioli PL. Common carotid arterial wall thickness in NIDDM subjects. Diab Care 1994;17:1330-6. 